\title{
Student Perceptions of an Online Post Graduate Course in Family Medicine in Sri Lanka
}

R. E. E. de Silva MBBS, DFM, MRCGP (Int)

Lecturer in Family Medicine

Faculty of Medicine

University of Colombo

E-Mail : erandie_ediriweera@yahoo.com

\section{J. Fernando MBBS, DFM}

Distance Education Coordinator in Family Medicine

Postgraduate Institute of Medicine

University of Colombo

E-Mail : joelfdo@gmail.com

\section{R. N. Sumanasekera MBBS}

Medical Officer

National Hospital of Sri Lanka

E-Mail : rndeepama@gmail.com

\section{S. D. Liyanagama MBBS}

Intern House Officer

National Hospital of Sri Lanka

E-Mail : sanlakshi@hotmail.com

D. P. de Silva.MBBS, PGCert-MedEdu(Col), DFM, MRCGP(Int)

Medical Officer

District Hospital

Moratuwa

E-Mail : dinushapp@yahoo.ca

Sri Lanka Journal of Bio-Medical Informatics 2010;1(4):205-13

DOI: 10.4038/sljbmi.v1i4.2247

\begin{abstract}
Background

The online Diploma course in Family Medicine (DFM) of the Post Graduate Institute of Medicine (PGIM) of the University of Colombo is one of the pioneering online post graduate medical courses in Sri Lanka.
\end{abstract}

\section{Objectives}

To describe student perceptions on the online DFM course 


\section{Methods}

The study population comprised of all the students (19) of the first batch of the course. Pretested self administered questionnaires were administered to all students. A Likert scale was used to assess the domains of teaching, learning, levels of understanding, and technical problems. The scale ranged from $1=$ ["poor / not useful/did not understand"] to $5=$ ["excellent/ very useful/ understood very well"]. A focus group discussion was carried out to strengthen the student perceptions, based on the themes which emerged.

\section{Results}

Response rate was $98.4 \%$. Levels of understanding the lessons were perceived to be high with an average of 4.8. Students were of the opinion that discussions and assignments helped them to engage in active learning. Online discussions were found to be the most useful form of learning. $88 \%$ commented that they are able to link clinical work to their online course work.

\section{Conclusions}

This online course has been useful in improving student knowledge and the levels of understanding of individual lessons are satisfactory. The most useful form of learning appeared to be online discussions.

Keywords: Online medical education; Family Medicine; Postgraduate diploma; Student perceptions.

\section{Introduction}

Online learning has important implications for globalization in medical education, and for the continuum of education from undergraduate to postgraduate and continuing medical education. Internet-based instruction is associated with favourable outcomes across a wide variety of learners, learning contexts, clinical topics, and learning outcomes ${ }^{(1)}$.

It has been demonstrated that Internet-based Continuing Medical Education (CME) programs are just as effective in imparting knowledge as traditional formats of CME ${ }^{(2)}$. Web based learning include a variety of internet technologies, instructional methods, and presentation formats to provide both asynchronous and synchronous forms of internet based medical education $^{(3)}$.

The online Diploma course in Family Medicine (DFM) of the Post graduate Institute of Medicine is one of the pioneering online distance education courses in the field of Medicine in Sri Lanka. This course was introduced in 2008 and currently two batches are undergoing training. Hence the aim of this study was to obtain student perceptions on the online teaching component of the online distance education Diploma in Family Medicine course.

\section{Course Design}

This is a two year course including four semesters. Each semester extends for six months. The course consists of two main components online learning and clinical work. The online 
Diploma in Family Medicine course is designed on the online Moodle Platform and has an asynchronous learning environment over a scheduled delivery period. Online learning / teaching activities consist of online lessons, online discussions, online assignments, quizzes, and other learning/ teaching activities with model answers. Reading material is posted online to facilitate learning theory and concepts.

Clinical training is in the form of 96 clinical teaching sessions in hospitals and general practices. Assessment comprises of formative assessment and summative assessment. Formative assessment includes assignments and the clinical portfolio, while the summative assessment is the final Diploma in Family Medicine examination.

\section{Methods}

This is a descriptive cross sectional study. The study population comprised of all the students of the first batch of the course. Custom designed self administered questionnaires in English were administered to all the students. The questionnaire assessed teaching/ learning of the course, level of understanding and usefulness of the lessons, technical aspects of the course using a Likert scale of 1-5. The scale ranged from 1 ["strongly disagree / not useful / did not understand"] to 5 ["strongly agree / very useful/ understood very well"]. Analysis was done using standard computer software. A focus group discussion (FGD) was held with the students to further strengthen the student perceptions. The themes of the focus group discussion were general course outline, online lessons, online discussions, assignments, quizzes other learning/teaching activities and technical aspects of the course. Data was recorded verbatim, collated and analyzed.

\section{Results}

A total of 19 students were enrolled in the course and the response rate was $98.4 \%$ as one student had left the course.

\section{Structuring of the course content}

Table 1. Student satisfaction on the structuring of the course content

\begin{tabular}{|l|l|}
\hline $\begin{array}{l}\text { Student response to: } \\
\text { Question: Structuring of the course content }\end{array}$ & $\begin{array}{l}\text { Percentage of } \\
\text { students }\end{array}$ \\
\hline Excellent & $17.6 \%$ \\
\hline Good & $76.4 \%$ \\
\hline Satisfactory & $5.8 \%$ \\
\hline Unsatisfactory & $0 \%$ \\
\hline Poor & $0 \%$ \\
\hline
\end{tabular}


Table 1 indicates the student perceptions regarding the satisfaction in structuring of the course content. Based on the results a total of $94 \%$ of students stated that the structuring of the course content was good or excellent.

Table 2. Clarity and usefulness of Learning Outcomes

\begin{tabular}{|l|l|}
\hline $\begin{array}{l}\text { Student response to: } \\
\text { Question: The Learning Outcomes } \\
\text { were clear and useful }\end{array}$ & $\begin{array}{l}\text { Percentage of } \\
\text { students }\end{array}$ \\
\hline Strongly agree & $17.6 \%$ \\
\hline Agree & $58.8 \%$ \\
\hline Agree to some extent & $23.5 \%$ \\
\hline Disagree & $0 \%$ \\
\hline Strongly disagree & $0 \%$ \\
\hline
\end{tabular}

*The survey question was rated along a 5-point Likert scale $(1=$ Strongly Disagree to $5=$ Strongly Agree).

Table 2 indicates the student response towards the clarity and usefulness of learning outcomes. A total of $76.4 \%$ of the students have agreed or strongly agreed that the learning outcomes were clear and useful.

\section{Online Lessons}

Table 3. Usefulness of lessons

\begin{tabular}{|l|l|l|l|l|l|}
\hline \multicolumn{2}{|l|}{ Student perception on usefulness of individual lessons } \\
\hline & Obsolete & $\begin{array}{l}\text { Not so } \\
\text { useful }\end{array}$ & $\begin{array}{l}\text { Somewhat } \\
\text { useful }\end{array}$ & Useful & Very useful \\
\hline Range & None & $0-11.7$ & $5.9-23.5$ & $17.6-47$ & $35.3-76.4$ \\
\hline $\begin{array}{l}\text { Mean } \\
\text { Average }\end{array}$ & 0 & 8.8 & 9.18 & 26.8 & 54.7 \\
\hline
\end{tabular}

Table 3 indicates the usefulness of online lessons to the students and the levels of understanding of the individual lessons. Mean percentages on the usefulness of the lessons for the categories useful and very useful were respectively 26.8 and 54.7, indicating that the most of the lessons being very useful to the students. The average mean score for the levels of understanding the individual lessons were perceived to be high with an average of 4.8 on a scale of 1-5. 


\section{Online Discussions}

Table 4. Online Discussions

\begin{tabular}{|c|c|c|c|}
\hline 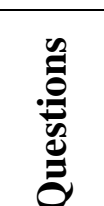 & & $\begin{array}{l}\text { Discussions are } \\
\text { useful in enhancing } \\
\text { knowledge }\end{array}$ & $\begin{array}{l}\text { Time duration was } \\
\text { adequate to permit } \\
\text { meaningful } \\
\text { interaction }\end{array}$ \\
\hline \multirow{5}{*}{ 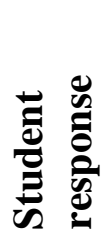 } & Strongly agree & $29 \%$ & $0 \%$ \\
\hline & Agree & $47 \%$ & $53 \%$ \\
\hline & Agree to some extent & $24 \%$ & $29 \%$ \\
\hline & Disagree & $0 \%$ & $6 \%$ \\
\hline & Strongly disagree & $0 \%$ & $12 \%$ \\
\hline
\end{tabular}

Table 4 indicates the usefulness of online discussions in enhancing knowledge and the adequacy of time to permit meaningful interaction. A majority of $76 \%$ of the students have agreed or strongly agreed that online discussions are useful in enhancing knowledge. While the majority of students felt that the time duration for discussions was adequate $18 \%$ of the students have felt that the time duration to be inadequate to permit meaningful interaction. Online discussions were found to be the most useful form of learning. Focus group discussion revealed that peer learning in discussions was helpful. One student commented that, "We were able to learn from colleagues too, by taking part in the discussions as they helped to see a problem from different angles, and give a broader view". Some students felt that some discussion topics were not good. Also they felt that the contribution from some of their colleagues was not very useful, as the "comments were more literal than factual".

\section{Online Assignments}

Table 5. Online Assignments

\begin{tabular}{|c|c|c|c|}
\hline 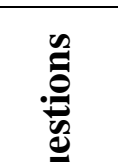 & & $\begin{array}{l}\text { Assignments are } \\
\text { useful in enhancing } \\
\text { knowledge }\end{array}$ & $\begin{array}{l}\text { Time allocated for } \\
\text { assignments were } \\
\text { adequate }\end{array}$ \\
\hline \multirow{5}{*}{ 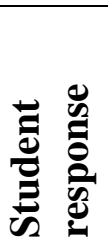 } & Strongly agree & $12 \%$ & $0 \%$ \\
\hline & Agree & $47 \%$ & $35 \%$ \\
\hline & Agree to some extent & $29 \%$ & $18 \%$ \\
\hline & Disagree & $12 \%$ & $35 \%$ \\
\hline & Strongly disagree & $0 \%$ & $12 \%$ \\
\hline
\end{tabular}

Table 5 indicates the usefulness of online assignments in enhancing knowledge and the adequacy of allocated time for assignments. 59\% of the students have agreed or strongly agreed that the assignments were useful in enhancing their knowledge. However, a 
significant proportion of students accounting to $47 \%$ have felt that the time duration allocated for the assignments to be inadequate. One student went on to state that, "In conventional teaching the teacher gets to know the student by face to face interactions, however in online learning it is important for the students to submit assignments, and participate in discussions as these will help the teachers to assess the students". Students also stated that, "Prompt feedback from the tutors will be useful, as this helps to learn from mistakes. Students felt that some tutors gave prompt feedback, some gave delayed feedback, while others gave no feedback". Trainees were of the opinion that online discussions and online assignments helped them to engage in active learning and that this helped them in problem solving when dealing with patient problems in practice.

\section{Online Quizzes}

$72 \%$ of the students have agreed or strongly agreed that the online quizzes were useful in enhancing their knowledge.

\section{Ability to link clinical work to online learning}

Table 6. Ability to link clinical work to online learning

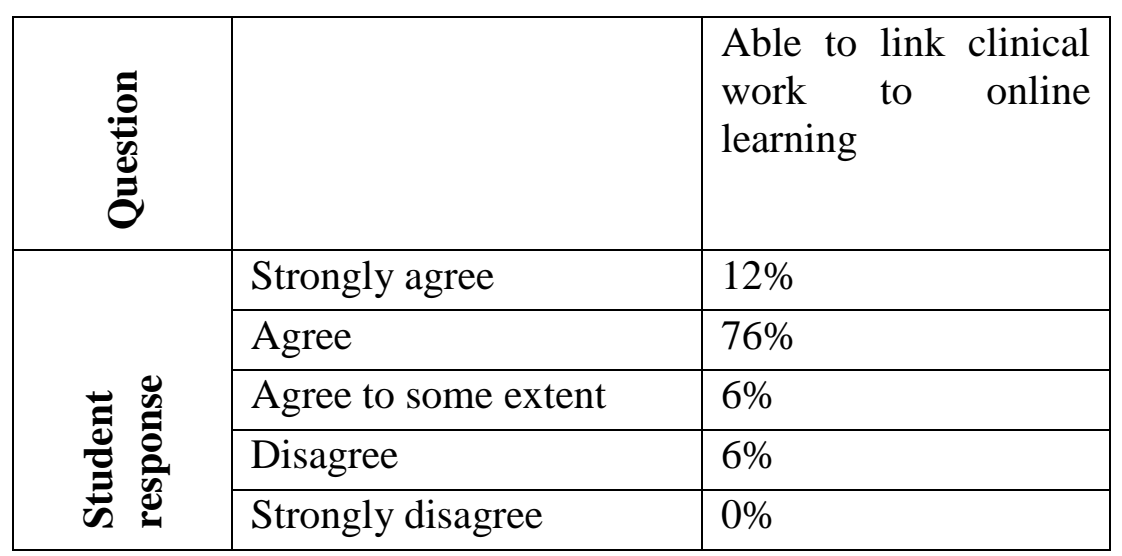

Table 6 indicates that a majority of $88 \%$ of the students had strongly agreed or agreed that they were able to link clinical work to online learning.

\section{Technical Issues}

Table 7 indicates that $88 \%$ of the students had used the help wanted help given facility. $76 \%$ responded that they did not have problems in uploading assignments while $88 \%$ have had no problems in downloading PDF files. In dealing with technical problems almost all the students felt that the technical skills workshop organized by the PGIM was helpful in obtaining working knowledge in "MOODLE" online learning environment and that technical assistance was available at the PGIM. 
Table 7. Technical aspects of the course

\begin{tabular}{|l|l|}
\hline Response & $\begin{array}{l}\text { Percentage } \\
\text { Students }\end{array}$ \\
\hline Often used Help wanted help given facility & $88 \%$ \\
\hline No problems in uploading assignments & $76 \%$ \\
\hline No problems in downloading PDF files & $88 \%$ \\
\hline $\begin{array}{l}\text { No problems in viewing videos available on } \\
\text { website }\end{array}$ & $76 \%$ \\
\hline
\end{tabular}

\section{Discussion}

Online learning has a number of benefits which allows it to be an attractive learning option among specific groups of learners. Internet-based education permits learners to participate at a time and place convenient to them, facilitates instructional methods that might be difficult in other formats, and has the potential to tailor instruction to individual learners' needs ${ }^{(1)}$. This is particularly important in postgraduate education among medical professionals who have to contend with their professional commitments which allows them little time to engage in traditional learning formats. The concept of online medical learning is still in its infancy in Sri Lanka, the teaching modalities are still undergoing refinement and it is important to assess both the learning outcomes and the satisfaction of the participants of this form of online learning. In this study we only focused on the aspect of student perceptions.

Based on our findings this online course has been useful to the students in improving their knowledge through online reading material, discussions, assignments and quizzes. The student satisfaction regarding structuring of the course content appeared to be high. The levels of understanding of individual lessons as perceived by the students were satisfactory, with an average mean score of 4.8. This correlates well with evidence from other studies which suggested a high level of student satisfaction with regard to comprehension of online lessons ${ }^{(4)}$. Outcome based studies have also demonstrated the efficacy of the online approach. In a comparative evaluation on web based teaching module for medical students versus the standard recommended text and tutor-led teaching revealed that the online module group had a significantly higher mean total knowledge score than the textbook group ${ }^{(5)}$.

It is evident from the focus group discussion that the online assignments and discussions facilitated by the tutors helped students to engage in active learning and that the students were able to apply the concepts and problem solving skills when dealing with real life patients. The high student satisfaction on online discussions is also probably due to the fact that the students could interact with their peers, which contributed towards peer learning. According to Spencer, adult learners are motivated by learning that is designed so that they can take responsibility for their own learning, learning that involves active participation and 
is problem based learning ${ }^{(6)}$. An undergraduate medical course introducing online case based teaching in Psychiatry also indicates that computer-delivered modules are popular with students ${ }^{(7)}$.

The majority of the students have felt that they are able to link their online learning to their clinical work. This may be due to the fact that the clinical training takes place hand in hand while the online lessons are conducted. Another study evaluating an undergraduate online clerkship in Family Medicine revealed that a carefully designed online curriculum could improve student confidence in key clinical skills related to humanistic practice ${ }^{(8)}$.

This course involved an asynchronous learning environment over a scheduled time period. Asynchronous interactivity is where participants are not engaged in online discussions at the same time. Somenarain et al. compared three formats of biology courses, an Asynchronous online course, a Synchronous online course and the traditional course, which revealed that there were no significant differences in the student course grades between the three groups ${ }^{(4)}$. In another study, Curran et al, noted that Scheduled Group Learning Internet based CME format facilitated learning through case-based asynchronous discussions with peers and a facilitator over a scheduled delivery period was able to result in more positive learning than an On Demand Internet-based CME format ${ }^{(9)}$.

\section{Limitations and suggestions}

This was only a descriptive study to explore the student perceptions on the course. Further studies are required to objectively assess attitudes, knowledge and skills gained through the course and also to compare with traditional formats of teaching. Also another limitation is the small sample size.

\section{Conclusion}

Students were satisfied with the course structure, learning outcomes, and the course as a whole. The students perceived that this online course has been useful in improving student knowledge and the levels of understanding of individual lessons were satisfactory. Students were able to link the online work to their clinical work. The most useful form of learning appeared to be online discussions.

\section{Acknowledgements}

Authors wish to acknowledge the Director / PGIM for granting permission to carryout the study. The authors are also grateful for all students who participated in the study.

\section{Authors' contributions}

REE De Silva and J Fernando designed the study, performed literature review and drafted the manuscript. Data collection and Focus group discussion were carried out by REE De Silva, J Fernando, DRN Sumanasekera, SD Liyanagama and DP de Silva. Data Analysis was by 
REE De Silva, SD Liyanagama. REE De Silva, J Fernando and DP De Silva critically revised the manuscript.

\section{References}

1. Cook DA, Levinson AJ , Garside S, Dupras D M, Erwin P J, Montori V M. InternetBased Learning in the Health Professions. Journal of American Medical Association 2008; 300:1181-1196. Available from: http://jama.amaassn.org/cgi/content/full/300/10/1181

2. Wutoh R, Boren SA, Balas EA. eLearning: A review of Internet based continuing medical education. Journal of Continuing Education in the Health Professions 2004; 24:20-30.

3. Curran V, Fleet L: A review of evaluation outcomes of web-based continuing medical education. Medical Education 2005, 39:561-67.

4. Somenarain L, Akkaraju S, Gharbaran R. Student Perceptions and Learning Outcomes in Asynchronous and Synchronous Online Learning Environments in a Biology Course. MERLOT Journal of Online Learning and Teaching 2010; 6: 353-357. Available from: http://jolt.merlot.org/vol6no2/somenarain_0610.pdf

5. Averns H, Maraschiello M, Van Melle E, Day A. Evaluation of a Web-based Teaching Module on Examination of the Hand. The Journal of Rheumatology 2009; 36:470-471. doi: 10.3899/jrheum.080761

6. Spencer J, Jordan R. Educational outcomes and leadership to meet the needs of modern health care. Quality in Health Care 2001; 10:38-45.

7. Hare E H, Evans P, McIntosh C E, Thomson LDG. Case-based online learning for medical undergraduates, Psychiatric Bulletin (2007) 31: 73-75. doi: 10.1192/pb.bp.106.010819

8. Wiecha JM, Markuns JF. Promoting Medical Humanism: Design and Evaluation of an Online Curriculum. Innovations in Family Medicine Education, 40;617.

9. Curran VR, Fleet LJ, Kirby F. A comparative evaluation of the effect of internet-based CME delivery format on satisfaction, knowledge and confidence. BMC Medical Education 2010, 10:10. Available from: http://www.biomedcentral.com/1472-6920/10/10 